\title{
Synthesis of novel tricyclic isoindole derivatives
}

\author{
Teresa M. V. D. Pinho e Melo, ${ }^{a, *}$ Catarina I. A. Santos, ${ }^{a}$ António M. d'A. Rocha Gonsalves, ${ }^{\mathrm{a}}$ \\ José A. Paixão, ${ }^{\mathrm{b}}$ Ana M. Beja ${ }^{\mathrm{b}}$ and Manuela Ramos Silva ${ }^{\mathrm{b}}$ \\ a Departamento de Química, Universidade de Coimbra, 3004-535 Coimbra, Portugal \\ ${ }^{\mathrm{b}}$ Departamento de Física, Universidade de Coimbra, 3004-516 Coimbra, Portugal
}

Received 8 July 2003; revised 3 September 2003; accepted 10 September 2003

\begin{abstract}
Novel 3-methylene-2,5-dioxo-3H,9bH-oxazolo[2,3- $a$ ]isoindoles were prepared from the thermolysis of (3R,9bS)-5-oxo2,3,5,9b-tetrahydrothiazolo[2,3-a]isoindole-3-carboxylic acids in acetic anhydride. The structure of 3-methylene-2,5-dioxo$3 H, 9 \mathrm{~b} H$-oxazolo[2,3- $a$ ]isoindole $\mathbf{6 a}$ was determined by X-ray crystallography.

(C) 2003 Elsevier Ltd. All rights reserved.
\end{abstract}

In relation with our ongoing research $^{1}$ we became interested in exploring the possibility of preparing 1,3thiazolidine-4-carboxylic acid fused to five-membered ring systems which could be used as potential münchnone precursors. Our target was the synthesis of 5-oxo2,3,5,9b-tetrahydrothiazolo[2,3-a]isoindole-3-carboxylic acids in order to study their reactivity.

The reaction of $L$-cysteine methyl ester with 2-carboxybenzaldehyde was carried out following the general procedure reported earlier for the synthesis of thiazolidines. $^{2}$ The product was purified simply by recrystallisation. This resulted in the direct diastereoselective synthesis of methyl $(3 R, 9 \mathrm{~b} S)-5$-oxo-2,3,5,9b-tetrahydro-thiazolo[2,3- $a$ ] isoindole-3-carboxylate 1a in $71 \%$ yield. Compound 1a has been reported with the incorrect stereochemistry, as being the $(3 S, 9 \mathrm{~b} R)$ stereoisomer. ${ }^{3}$ It derives from $L$-cysteine thus the configuration of C3 must be $R .^{4,5}$ Methyl $(3 R, 9 \mathrm{~b} S)$-5-oxo-2,3,5,9b-tetrahydrothiazolo[2,3- $a$ ]isoindole-3-carboxylate $\mathbf{1 a}$ was converted into the corresponding acid $\mathbf{2 a}$ in $91 \%$ yield $\left([\alpha]_{\mathrm{D}}^{25}=-343, c 0.1, \mathrm{EtOH}\right)$ by the reaction with lithium iodide in ethyl acetate and treatment with aqueous $\mathrm{HCl}$, following a known synthetic procedure previously reported $^{1 \mathrm{a}, 1 \mathrm{c}}$ (Scheme 1).

Oliver et al. reported the synthesis of 5-oxo-2,3,5,9b-tetrahydrothiazolo[2,3- $a$ ] isoindole-3-carboxylic acid $\mathbf{2 a}$ directly from the reaction of 2-carboxybenzaldehyde with cysteine hydrochloride in the presence of pyridine. ${ }^{6}$ However, the stereochemistry of the product was not mentioned. We repeated this synthetic procedure which led to compound 2a $(58 \%),[\alpha]_{\mathrm{D}}^{25}=-343(c 0.1, \mathrm{EtOH})$. This value for the optical rotation indicates that the diastereoselectivity of this process was the same as the one observed for the route described above.

The reactivity of compound $\mathbf{2} \mathbf{a}$ as a münchnone precursor was studied. Attempts were made to promote cyclodehydration by heating at reflux a solution of
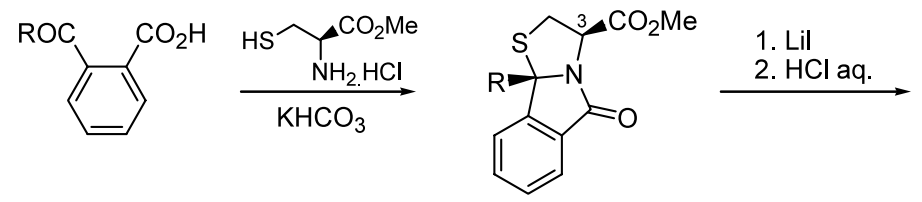

1a, $\mathrm{R}=\mathrm{H} \quad 71 \%$

1b, $\mathrm{R}=\mathrm{CH}_{3} \quad 75 \%$

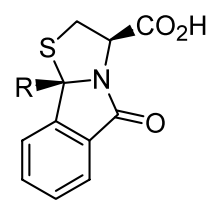

2a, $\mathrm{R}=\mathrm{H} \quad 91 \%$

2b, $\mathrm{R}=\mathrm{CH}_{3} \quad 85 \%$

Scheme 1.

Keywords: diastereoselectivity; thiazolo[2,3- $a$ ]isoindoles; 3-methylene-2,5-oxazolo[2,3- $a$ ]isoindoles.

* Corresponding author. Fax: +351 239 826068; e-mail: tmelo@ci.uc.pt 


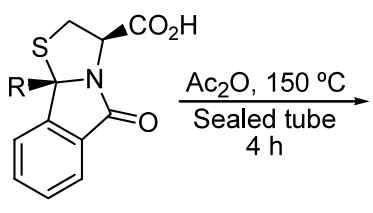

2a, $\mathrm{R}=\mathrm{H}$

2b, $\mathrm{R}=\mathrm{CH}_{3}$

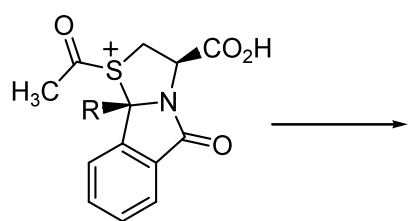

3a, $\mathrm{R}=\mathrm{H}$

3b, $\mathrm{R}=\mathrm{CH}_{3}$<smiles>[R]C1=[N+]([C@@H](CSC#C)C(=O)O)C(=O)c2ccccc21</smiles>

4a, $\mathrm{R}=\mathrm{H}$

4b, $\mathrm{R}=\mathrm{CH}_{3}$

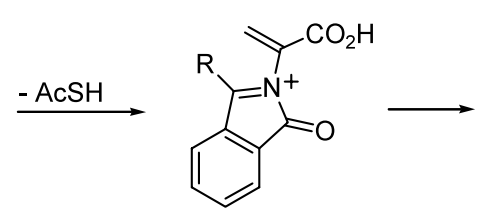

5a, $\mathrm{R}=\mathrm{H}$

5b, $\mathrm{R}=\mathrm{CH}_{3}$<smiles>[R]C12OC(=O)C(=C)N1C(=O)c1ccccc12</smiles>

$\mathbf{6 a}, \mathrm{R}=\mathrm{H} \quad 37 \%$

6b, $\mathrm{R}=\mathrm{CH}_{3} \quad 64 \%$

Scheme 2.

compound 2a in acetic anhydride in the presence of dimethyl acetylenedicarboxylate. However, the expected $1 H, 3 H$-pyrrolo[1,2-c]thiazole was not obtained even when prolonged heating was used.

Nevertheless, we carried out the reaction of $(3 R, 9 \mathrm{~b} S)-5$ oxo-2,3,5,9b-tetrahydrothiazolo[2,3- $a$ ] isoindole- 3 -carboxylic acid 2a with acetic anhydride and dimethyl acetylenedicarboxylate in a sealed tube. The solution was heated at $150^{\circ} \mathrm{C}$ for $4 \mathrm{~h}$. Although no 1,3-dipolar cycloadduct was obtained, this study led to an interesting result. We isolated one product in $37 \%$ yield which was identified as 3-methylene-2,5-dioxo-3 $\mathrm{H}, 9 \mathrm{~b} H$-oxazolo[2,3-a] isoindole $\mathbf{6 a}^{7}$ (Scheme 2). The structure of $\mathbf{6 a}$ was determined by X-ray crystallography as illustrated in Figure 1.

The mechanism proposed for the formation of compound 6a is outlined in Scheme 2. The first step is the acetylation of the sulfur atom with acetic anhydride giving 3a followed by a ring-opening reaction. The elimination of thioacetic acid from compound $4 \mathbf{a}$ leads

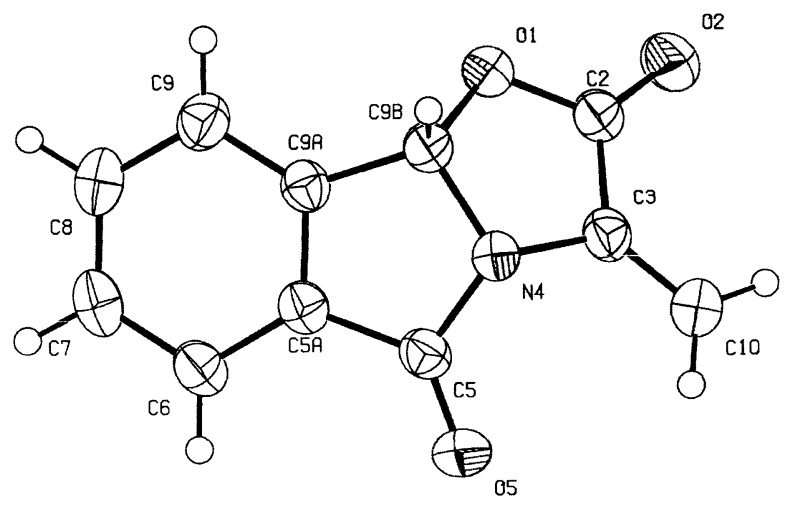

Figure 1. ORTEPII plot of 3-methylene-2,5-dioxo-3H,9b $H$ oxazolo[2,3-a]isoindole 6a with anisotropic displacement ellipsoids calculated at the $50 \%$ probability level. to $N$-acyliminium ion 5a. This intermediate undergoes a 5-endo-trig cyclisation reaction with formation of 3-methylene-2,5-dioxo-3H,9b $H$-oxazolo[2,3- $a$ ] isoindole 6a.

The process can be regarded as involving the formal elimination of the elements of $\mathrm{SH}$ from $(3 R, 9 \mathrm{~b} S)-5$ oxo-2,3,5,9b-tetrahydrothiazolo[2,3- $a$ ] isoindole-3-carboxylic acid 2a followed by cyclisation. It represents the synthesis of isoindole derivative (6a), a new member to a class of compounds having a significant number of applications. ${ }^{2,8}$

In order to determine the scope of this route to 3-methylene-2,5-dioxo-3 $H, 9 \mathrm{~b} H$-oxazolo[2,3- $a$ ]isoindoles we prepared $\quad(3 R, 9 \mathrm{~b} S)-9 \mathrm{~b}$-methyl-5-oxo-2,3,5,9b-tetrahydrothiazolo[2,3-a]isoindole-3-carboxylic acid $\mathbf{2 b}$ (Scheme 1). When the reaction of $L$-cysteine methyl ester with 2-acetylbenzoic acid was carried out at room temperature with a reaction time of $30 \mathrm{~min}(3 R, 9 \mathrm{~b} S)$ $9 \mathrm{~b}$ - methyl - 5 - oxo - 2,3,5,9b - tetrahydrothiazolo[2,3 - $a$ ]isoindole-3-carboxylate $\mathbf{1 b}$ was obtained in $18 \%$ yield. Changing the reaction time to $12 \mathrm{~h}$ led to compound $\mathbf{1 b}$ in $28 \%$ yield. The best result was obtained performing the reaction in the presence of sodium acetate in refluxing toluene for $5 \mathrm{~h}(75 \%)$. The reported value for the optical rotation of compound $\mathbf{1 b}$ is $[\alpha]_{\mathrm{D}}^{25}=-289.6^{3}(c$ $\left.1.75, \mathrm{CHCl}_{3}\right)$ in contrast with the value of $[\alpha]_{\mathrm{D}}^{25}=-328.7$ (c $1.75, \mathrm{CH}_{2} \mathrm{Cl}_{2}$ ) obtained for the same compound prepared by our synthetic procedure. Compound $\mathbf{2 b}$ was obtained from $\mathbf{1 b}$ in $85 \%$ yield.

We carried out the reaction of $(3 R, 9 \mathrm{~b} S)-9 \mathrm{~b}-$ methyl-5oxo-2,3,5,9b-tetrahydrothiazolo[2,3- $a$ ] isoindole-3-carboxylic acid $\mathbf{2 b}$ with acetic anhydride in a sealed tube (Scheme 2). The solution was heated at $150^{\circ} \mathrm{C}$ for $4 \mathrm{~h}$. In a process analogous to that described for the synthesis of oxazolo[2,3- $a$ ] isoindole derivative 6a, compound 2b was converted into the new tricyclic isoindole derivative 9b-methyl-3-methylene-2,5-dioxo-3 $\mathrm{H}, 9 \mathrm{bH}$ - 
oxazolo[2,3- $a$ ]isoindole $\mathbf{6 b}^{7}$ in $64 \%$ yield. When the reaction of $\mathbf{2 b}$ with acetic anhydride was performed in the presence of dimethyl acetylenedicarboxylate (sealed tube, $150^{\circ} \mathrm{C}, 4 \mathrm{~h}$ ) compound $\mathbf{6 b}$ was isolated but in lower yield $(40 \%)$ but no 1,3-dipolar cycloadduct was formed.

In conclusion, we report a synthetic methodology to new tricyclic isoindole derivatives, 3-methylene-2,5dioxo-3H,9bH-oxazolo[2,3- $a$ ]isoindoles through the thermolysis of $(3 R, 9 \mathrm{~b} S)-5$-oxo-2,3,5,9b-tetrahydrothiazolo[2,3- $a$ ] isoindole-3-carboxylic acids in acetic anhydride. Work is in progress to further investigate the scope of this and other related reactions as a route to new tricyclic ring systems.

\section{Acknowledgements}

Financial support from Chymiotechnon and Fundação para a Ciência e a Tecnologia (POCTI/36137/QUI/ 2000) is gratefully acknowledged.

\section{References}

1. (a) Pinho e Melo, T. M. V. D.; Barbosa, D. M.; Ramos, P. J. R. S.; Rocha Gonsalves, A. M. d'A.; Gilchrist, T. L.; Beja, A. M.; Paixão, J. A.; Silva, M. R.; Alte da Veiga, L. J. Chem. Soc., Perkin Trans. 1 1999, 1219-1223; (b) Pinho e Melo, T. M. V. D.; Soares, M. I. L.; Barbosa, D. M.; Rocha Gonsalves, A. M. d'A.; Paixão, J. A.; Beja, A. M.; Silva, M. R.; Alte da Veiga, L. Tetrahedron 2000, 56, 3419-3424; (c) Pinho e Melo, T. M. V. D.; Soares, M. I. L.; Rocha Gonsalves, A. M. d'A.; Paixão, J. A.; Beja, A. M.; Silva, M. R.; Alte da Veiga, L.; Pessoa, J. C. J. Org. Chem. 2002, 67, 4045-4054; (d) Pinho e Melo, T. M. V. D.; Gomes, C. S. B.; Rocha Gonsalves, A. M. d'A.; Paixão, J. A.; Beja, A. M.; Ramos Silva, M.; Alte da Veiga, L. Tetrahedron 2002, 58, 5093-5102.

2. Gilchrist, T. L.; Rocha Gonsalves, A. M. d'A.; Pinho e Melo, T. M. V. D. Tetrahedron 1994, 50, 13709-13724.

3. Allin, S. M.; Vaidya, D. G.; Page, M. I.; Slawin, A. M. Z. ARKIVOC 2000, 1, 151-157.

4. The reported value for the optical rotation of compound 1a is $[\alpha]_{\mathrm{D}}^{25}=-233.6^{3}\left(\right.$ c $\left.2.31, \mathrm{CHCl}_{3}\right)$ in contrast with the value of $[\alpha]_{\mathrm{D}}^{25}-400.5\left(c\right.$ 2.3, $\left.\mathrm{CH}_{2} \mathrm{Cl}_{2}\right)$ obtained for the same compound prepared by our synthetic procedure. This result suggests that 1a was obtained in a much higher diastereoisomeric excess since a positive value for the optical rotation of $N$-acyl-2-substituted-thiazolidine-4-carboxylates is usually associated with $(2 R, 4 R)$ stereochemistry whereas a negative value is associated with $(2 S, 4 R)$ stereochemistry., ${ }^{1,5 \mathrm{a}, \mathrm{b}}$ The structure of 1a was established by X-ray crystallography, a result to be disclosed in a specific paper.

5. (a) Szilágyi, L.; Györgydeák, Z. J. Am. Chem. Soc. 1979, 101, 427-432; (b) Györgydeák, Z.; Kajtár-Peredy, M.; Kajtár, J.; Kajtár, M. Liebigs Ann. Chem. 1987, 927-934; (c) Benedini, F.; Ferrario, F.; Sala, A.; Sala, L.; Soresinetti, P. A. J. Heterocycl. Chem. 1994, 31, 13431347.

6. Oliver, G. L.; Gates, J. W., Jr. J. Am. Chem. Soc. 1958, 702-707.

7. General procedure for the synthesis of 3-methylene-2,5dioxo-3H,9bH-oxazolo[2,3-a]isoindoles $\boldsymbol{\sigma a}$ and $\boldsymbol{\sigma b}$. A solution of 5-oxo-2,3,5,9b-tetrahydrothiazolo[2,3-a]isoindole3-carboxylic acid (2a or $\mathbf{2 b})(1.28 \mathrm{mmol})$ in $\mathrm{Ac}_{2} \mathrm{O}(2.6 \mathrm{ml})$ was heated, in a sealed tube, at $150^{\circ} \mathrm{C}$ for $4 \mathrm{~h}$. The reaction was cooled to room temperature and was diluted with dichloromethane $(50 \mathrm{ml})$. The organic phase was washed with a saturated aqueous solution of $\mathrm{NaHCO}_{3}$ and with water, dried $\left(\mathrm{MgSO}_{4}\right)$ and evaporated. The crude product was purified by flash chromatography [hexane-ethyl acetate $(2: 1)]$.

3-Methylene-2,5-dioxo-3H,9bH-oxazolo[2,3-a]isoindole 6a: obtained as a solid (37\%). Mp $174.2-176.0^{\circ} \mathrm{C}$ (from ethyl ether). $\delta_{\mathrm{H}}\left(\mathrm{CDCl}_{3}, 300 \mathrm{MHz}\right) 5.93(1 \mathrm{H}, \mathrm{d}, J=1.4 \mathrm{~Hz}), 5.96$ $(1 \mathrm{H}, \mathrm{d}, J=1.4 \mathrm{~Hz}), 6.51(1 \mathrm{H}, \mathrm{s}), 7.68-7.79(3 \mathrm{H}, \mathrm{m}, \mathrm{Ar}-\mathrm{H})$, 7.95-7.97 $(1 \mathrm{H}, \mathrm{Ar}-\mathrm{H}) ; \delta_{\mathrm{C}}\left(\mathrm{CDCl}_{3}, 75.5 \mathrm{MHz}\right) 87.0,107.9$, $125.1,125.5,130.1,131.7,131.9,134.4,141.1,165.2$ and 169.3; $m / z 201\left(\mathrm{M}^{+}, 33 \%\right), 172(4), 157$ (41) and 133 (100). The crystal structure of $\mathbf{6 a}$ has been deposited at the CCDC with the deposition number CCDC 218858.

8. (a) Takahashi, I.; Kawakami, T.; Hirano, E.; Yokota, H.; Kitajima, H. Synlett 1996, 353-355; (b) Mertens, A.; Zilch, H.; König, B.; Schäfer, W.; Poll, T.; Kampe, W.; Seidel, H.; Leser, U.; Leinert, H. J. Med. Chem. 1993, 36, 25262535; (c) Schäfer, W.; Friebe, W.-G.; Leinert, H.; Mertens, A.; Poll, T.; von der Saal, W.; Zilch, H.; Nuber, B.; Ziegler, M. L. J. Med. Chem. 1993, 36, 726-732; (d) Clercq, E. J. Med. Chem. 1995, 38, 2491-2517; (e) Allin, S. M.; Vaidya, D. G.; Page, M. I.; Slawin, A. M. Z.; Smith, T. Tetrahedron Lett. 2000, 41, 2219-2222. 